\title{
Developing Partnership Approaches to Tourism in Central and Eastern Europe
}

\section{Lesley Roberts and Fiona Simpson}

Leisure and Tourism Management Department, Scottish Agricultural College, Auchincruive, Ayr KA6 5HV, Scotland, UK

In many of the former socialist countries of Central and Eastern Europe (CEE), the concept of developing wider involvement within decision making-processes remains inherently problematic. Prior to 1989 , public participation was a limited and often ignored aspect of policy making. However, more recently throughout the region, tourist agencies, new regional organisations, a range of non-governmental organisations, and community groups have emerged in response to potential growth in new tourism industries, thus expanding the number of stakeholders involved. This paper investigates collaboration and partnership working in two rural regions of Bulgaria and Romania, countries unable to match the performance of their CEE counterparts where tourism development is concerned. It provides a reflective analysis of achievements within a framework of prerequisites to successful partnership working. Although both examples illustrate the emergence of new development practices, the paper questions their sustainability. The analysis identifies a number of elements, common to both cases, that illustrate the need to focus the evaluation of partnership working on long-term processes rather than short-term, more measurable outcomes.

\section{Introduction}

This paper evaluates the outcomes of two case studies of rural tourism development in two neighbouring countries of south-east Europe, Romania and Bulgaria. Focus is placed on the extent to which each case study approximates to what might be considered as successful collaboration and partnership working with a particular emphasis on the intangible elements of new social practices. The paper achieves its aims in three stages, by:

(1) Identifying factors critical to successful partnerships

(2) Evaluating the presented case studies in relation to these factors

(3) Analysing the outcomes of each and identifying where intangible elements of social relations may prevent sustainable practice whilst still ostensibly satisfying the requirements of development projects.

In recent decades, several influences have altered perceptions of tourism planning and perhaps none more that notions of sustainability. Planning and development processes that fit within the concept indicate a growing aw areness that tourism should aim to contribute towards sustainable development (Gunn, 1994). More recently, efforts to create sustainability in tourism development have focused on social sustainability and a community development approach (Joppe, 1996) reflecting increasing recognition given to the roles played by local communities. As a result, local participation has become the cornerstone of successful tourism in many circumstances and thus 'local communities' augment the growing list of recognised stakeholders in the tourism industry. 
The 'stakeholder society', largely a construct of the 1990s, may be seen as 'an increasingly necessary corrective to free-market capitalism' (Robson \& Robson, 1996) providing a platform for the articulation of needs by a number of groups in the interests of consensus. This implies that stakeholders need to be identified and drawn into decision-making processes. Such a belief echoes the principles of participative planning which aim to decentralise tourism planning and integrate it into overall community objectives thus requiring greater community involvement (Simmons, 1994). In this sense, stakeholder theory existed long before its recent popularisation, being an integral part of community tourism planning. A number of characteristics have been linked with the collaboration process. The independence of stakeholder groups is paramount as is an equality, no one group holding the balance of power. It should be recognised as an 'emergent process' where groups learn to manage their changing environments, and there should be joint ownership of decisions and a collective responsibility for progress (Gray in Jamal \& Getz, 1995: 189).

Partnership working and its related theoretical background have developed alongside this growing concern for stakeholder interaction. Within rural tourism, local partnerships are increasingly recognised as an appropriate policy response, particularly as a result of their ability to bring together the full range of interest groups in developing a coherent and sociopolitically inclusive planning approach (OECD, 1993: 65). Their achievement has been difficult within the international development domain, non-governmental development organisations (NGDOs) generally having shown little ability to develop partnerships amongst themselves (Fowler, 1998). Indeed, Fowler states 'there are so few NGDO partnerships around today which have the qualities of true partnership that one might expect the term to have been quietly dropped'. He cites the inability of partner organisations to strike a relational balance that empowers both as one reason for failure. Other writers also focus on power relations in community-based tourism planning (Reed, 1997; Joppe, 1996). Theories of collaboration need to focus on power relations as an explanatory variable that demonstrates why collaboration fails or succeeds (Reed,1997). This is different from viewing them as instrumental variables which places the focus on the achievement of a balance of power within an assumed pluralism with its attendant equality of access. By following the types of consultation prescribed by pluralists, only the important and concrete decisions visible within the community will be dealt with, merely reproducing any bias that exists and excluding rather than including a wider range of stakeholder groups (Murphy, 1985; Joppe, 1996).

Although many advocate the involvement of local communities within partnerships, few evaluate the attempts made to achieve it (Simmons, 1994). Research focusing on collaborative approaches to community based tourism planning has highlighted the multiplicity of agencies involved in the tourism planning process, and the importance of understanding the interaction of institutions and stakeholders in order to ensure a successful outcome from such activities (Jamal \& Getz, 1995; Reed, 1997). Much of the research to date has overlooked the potential benefits of developing partnership approaches, confining itself instead to defining and detailing the nature of collaboration and integrated community-based development in a less formal sense. Furthermore, there is little 
analysis that determines the factors critical to success in the community tourism development process (Joppe, 1996).

Hall (1994) states that the dynamics of interaction of the many and varied interest groups involved in tourism development, and the influence of power and values on decision-making processes have been largely neglected in the study of tourism. Similarly, whilst the World Tourism Organisation (WTO) states that 'organisational structures for tourism must be carefully established, with emphasis on coordination among government agencies and between the public and private sectors' (1994: 240), it falls short of advocating more formal interaction of 'communities of interest' (Slee \& Snowden, 1997) through establishing partnership approaches. More recently, this has been confirmed by Reed, who suggests that the theoretical underpinning of community-based tourism planning remains relatively poorly developed (1997: 566). The literature on collaboration and power relations within rural tourism planning has highlighted the need to identify and discern between factors which are unique to each case, and those which can be applied to wider examples in developing practice (Reed, 1997: 588). Jamal and Getz (1995) support this, arguing for research focusing on the implementation of the theoretical constructs.

There is a clear need for empirical material that identifies practices and evaluates their effectiveness with a given context. This paper therefore compares two cases of rural development, one in Romania and the other in Bulgaria, in an effort further to explore concepts of partnership working. The post socialist setting emphasises the complex nature of partnership dynamics, and reflects the importance of intangible elements that underpin emerging working relationships and processes.

\section{Frameworks for Analysis of Rural Partnerships}

Amounting to more than ad hoc or periodic interaction between public and private sectors, partnerships establish longer-term, cross-institutional frameworks. In terms of key characteristics, partnerships are often formal, based on willingness of partners to cooperate and the identification of explicit common goals (OECD, 1990: 18). They provide access to decision making processes for all involved, thus including a range of actors in the policy-making process. In many cases, the experiences of western advanced capitalist countries have demonstrated that partnership working brings added value to development initiatives. Partnerships are widely recognised as important in promoting strategic, long-term thinking, and often their results are flexible and innovative, producing policies which are responsive to local needs (Chapman, 1998: 3). Chapman goes on to point out that despite their clear advantage in securing effective forms of governance, experiences in the west have shown that partnerships are complex; working with them can be unstructured, and is often beset with difficulties.

Examination of experiences at the local level within CEE countries provides a particularly useful insight into processes involved in establishing and developing partnership working, as a result of the relative unfamiliarity with the concepts involved. In particular, the lack of coordination within the diffuse field of tourism (Jamal \& Getz, 1995) is of interest given current fragmentation of local government responsibilities (Elander, 1997; Horvath, 1997; Pickvance, 1997). In 
addition, the lack of identified social and cultural acceptance of collaboration may provide a further obstacle to popular participation (Brenner, 1993; Hunya, 1996; Wyzan, 1997). Similarly, the complex relationship between public and private sectors which has emerged in the region during the 1990s adds a further dimension in evaluating the role of partnership working.

Within the policy guid ance and theoretical literature relating to partnerships, a wide range of criteria has been identified as critical to the success of partnership working. A number of these requirements are of particular interest in exploring the scope for partnership in rural tourism within the post-socialist context. Recognition of a shared problem, opportunity for each of the partners to benefit from its resolution, motivation and commitment are identified by the OECD (1997: 33) as primary conditions necessary for the formation and success of a partnership. Within these domains, a range of practical aspects can be identified. These must be addressed if effective partnership can be achieved.

As a framework for the comparative evaluation of the case studies, the following criteria are of particular interest (Table 1). They result from the need identified by Simmons (1994), Jamal and Getz (1995) and Reed (1997) to further our understanding of collaborative processes through analysis of practice rather than theory, and provide the structure for such analysis. They relate to the key conditions facilitating tourism planning collaborations at the community level.

Table 1 Factors critical to successful partnership working

\begin{tabular}{||l|l||}
\hline 1 & $\begin{array}{l}\text { Recognition of a high degree of interdependence in planning and managing the } \\
\text { domain/project }\end{array}$ \\
\hline 2 & $\begin{array}{l}\text { Recognition of individual and / or mutual benefits to be derived from the collab- } \\
\text { orative process }\end{array}$ \\
\hline 3 & A perception that decisions arrived at will be implemented \\
\hline 4 & The inclusion of key stakeholder groups \\
\hline 5 & $\begin{array}{l}\text { The appointment of a legitimate convenor to initiate and facilitate commu- } \\
\text { nity-based collaboration }\end{array}$ \\
\hline 6 & Formulation of aims and objectives \\
\hline
\end{tabular}

Source: Jamal \& Getz, 1995: 195-199

The following case studies explore early attempts at partnership working within rural tourism in mountain areas of Romania and Bulgaria, and the resulting analysis takes place in relation to these criteria.

\section{Introduction to the case studies}

Whilst the growth of tourism in CEE can be identified by increases in tourist arrivals, the rate of this growth is declining (WTO, 1995, 1997). The marked increase at the start of the 1990s was not sustained, and subsequent growth shows varying rates between different countries. But even accounting for the problems of data collection and analysis (Hall, 1990,1997), it is clear that neither Romania nor Bulgaria have been able to match the performance of other CEE countries in terms of tourism growth and development, each showing falls in international tourist arrivals throughout the first half of the decade (Hunt, 1993; Hall, 1995; WTO, 1997). Neighbouring countries in south-eastern Europe, both 
have been beset by continued political instability throughout the 1990s. Bulgaria's overall development was held back by a considerable foreign debt (Great Britain Foreign and Commonwealth Office, 1992), and its tourism development by the saturation of markets by other CEE tourists (Kerpel, 1990). Romania suffered the additional problem of adverse media coverage, affecting its image as a potential holiday destination.

It would be erroneous to suggest, however, that Romania and Bulgaria share common problems and potential solutions with regard to their tourism development. Both countries share similar characteristics to form the basis of a tourism experience - a common coastline, historic cities, plentiful mountain zones, and relatively unexplored cultures and religions. Each, however, has a distinctive culture resulting from, for example, different climates and geographies, relations with neighbouring countries, and responses to economic reforms of the $1980 \mathrm{~s}$ and 1990s.

Each case study by itself provides an interesting example of partnership working. Together, they allow comparison of different experiences within similar environments thereby adding to our understanding of factors critical to success in partnership working - both in a general sense and in relation to the specifics of a case.

As with much social research, the choice of methodologies involved issues and perspectives from a number of different approaches, each of which has its roots in different disciplines and perspectives. Approaches based in realism influenced the researchers' choice significantly. Unlike behaviourism, which concentrates on cause and effect and predictive behaviour and thus focuses on the future, realism aims to uncover structures of social relations in order to understand existing policies and practices (May, 1993). Whilst empirical research aims to establish facts, the realism approach has helped the researchers to investigate the structures of social relations which help to explain not merely what the outcomes are, but why they may have occurred. It focuses on the subjective states of actors involved in processes, and the meanings given to social relations.

Following such principles, the information for both case studies was collected over a period of years. In Romania, visits to study the research project and to collect information spanned more than four years between 1994 and 1998. In Bulgaria, formal participation in a research and consultancy project led to four visits over a three-year period ending in September, 1999. In both cases, regular contact with key contributors to development processes was maintained throughout the duration of the studies. Findings are not based on survey data but on evaluations of formal and informal interview processes, and participant observation of partnership-building processes thus allowing the research to reveal a number of complex realities that were socially constructed. Throughout, the roles of reflective practitioner (Schon, 1991) were adopted. These methods follow directly the principles of ethnographic research (Yin, 1993).

\section{Piloting Rural Tourism in Romania}

The Romanian case study explores the extent to which the rural tourism pilot scheme has provided opportunities for collaboration, partnerships, and inclusive, community-based participation. It raises these issues in a country with a 
history of top-down, 'super-centralised' (Popescu, 1993) planning and control which provided local populations with little or no experience of participatory decision-making. The shaping of people's attitudes has put obstacles in the way of change (Brenner, 1993). It would therefore not be unreasonable for people used to constraint in local decision-making (Turnock, 1996) to be slow to respond positively to calls for active participation.

Romania has a wide range of natural and cultural features attractive to tourists, most of them in rural areas, and rural tourism development is now seen as a way of creating a new service industry as traditional manufacturing industries decline. Increasing numbers of rural householders now offer bed and breakfast accommodation to visitors, and entire rural communities now find themselves drawn into tourism as a potential economic future.

Early reforms created a new Ministry of Tourism in 1992, the work of which encompassed that of its predecessor, the Officul $\mathrm{Nathional} \mathrm{de} \mathrm{Turism.} \mathrm{One} \mathrm{of} \mathrm{the}$ first tasks of the new ministry was the production of a 10-year tourism master plan identifying development needs at a central level, as well as decentralised measures such as the consolidation of vocational associations, the support of local initiatives in urban tourism, and the development of tourism in rural areas. Increasing recognition was given to the role of the private sector in tourism development processes as well as the need to develop a flexible and demand-led ind ustry. Legislation in 1994 established the framew ork for the national development of a rural tourism industry and a sum of 900,000 ECU was provided by the European Union (EU) Phare programme.

A major donor requirement was the key involvement of non-government organisations in the development process; this established the first partnership framework. A Romanian NGO, Asociața Naționala de Turism Rural, Ecologic Și Cultural (ANTREC), was quickly established to take responsibility for the coordination of an accommodation booking system, the identification of training needs and the delivery of training as appropriate, and the marketing and promotion of the rural tourism industry. Operation Villages Roumains (OVR), an international NGO familiar with rural development work in the country, was appointed with the remit of developing a rural infrastructure that would support tourism's development through, for example, the provision of waymarked footpaths, local maps and signage, and picnic and simple recreation sites. The organisations were to work together, one aim being the transfer of know-how between the two, primarily to enable ANTREC, inexperienced in decentralised capacity-building, to develop new ways of working. Figure 1 shows partnership relationships as they were established and operational from 1994 until 1997.

Bran Village, approximately $25 \mathrm{~km}$ south-west of the county town of Brasov, was the focus of pilot developments of both ANTREC and OVR and thus the area most likely to benefit from joint activities. The village, at the heart of Bran Zone, sits between the peaks of Mount Bucegi and the Piatra Craiului (King's Rock) on the borders of the Fagara\$ Mountains, providing spectacular views throughout the year. Extremely popular with domestic tourists, Bran is also familiar with the international tourist trade as day trippers, often from the nearby ski resort, and other coach tours regularly visit the castle. Bran Castle was reputed to have links with Vlad the Impaler. Perhaps more responsible for its international fame, it is claimed to be the former residence of Bram Stoker's Count Dracula. 


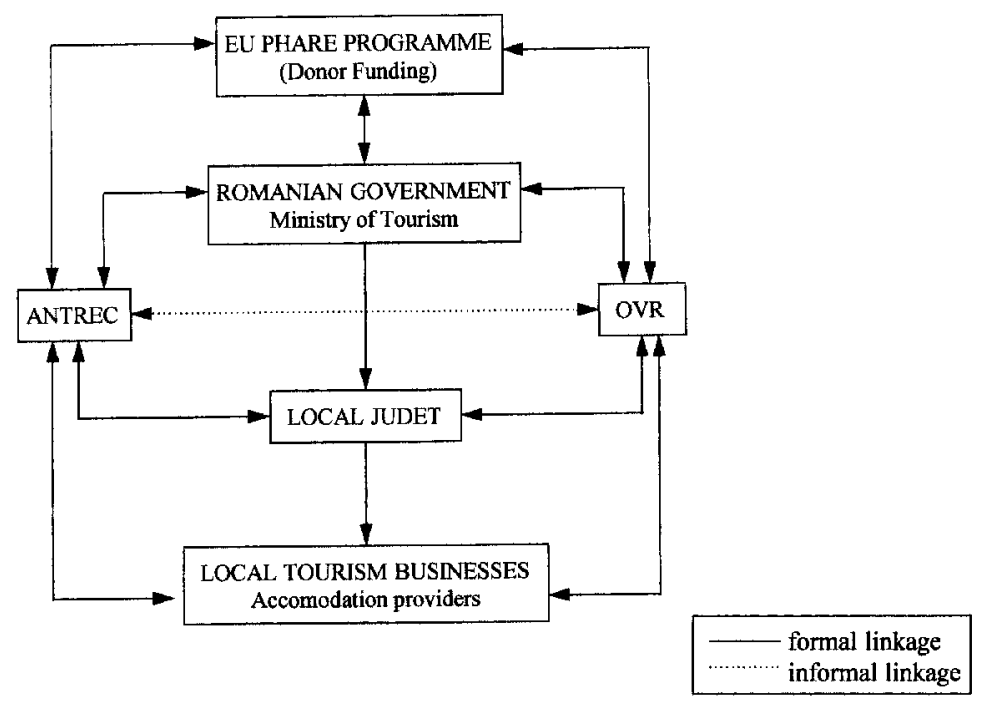

Figure 1 Romania: Extent of collaborative working as at 1997

Yet despite the area's beauty and the existence of a key visitor attraction amongst a number of interesting features, the achievements of the rural tourism development programme have been less than anticipated, perhaps reflecting the significance of the inherited difficulties in the country as a whole which serve to hinder the restructuring process. Despite the victory of a 1996 coalition government replacing earlier Iliescu governments, there remains a bureaucracy, well secured within post-socialist administrative structures, that has yet to become comfortable with ideas of transparency and accountability (Eyal, 1994; Economist, 1996; East European Newsletter, 1998; Hunya, 1998). Such a 'reform-communist' (Hunya, 1998) administration hampers processes of change and frustrates the efforts of those whose aims are decentralisation of control and wider access to decision-making processes.

Figure 1 shows the limited extent of partnerships in the early stages of the pilot programme despite the fact that tourism provision was entirely private sector led and community driven having been in existence prior to the establishment and involvement of ANTREC and OVR. Given a mistrust of centralisation, and its rejection in an emerging culture of individual enterprise, it is perhaps understandable that the in terest of local people in a centralised pilot project was limited and that an existing fragmentation of activities continued. Membership of ANTREC, the national association, was always lower than anticipated and insufficient to sustain the organisation's existence in the long term. The quasi-governmental nature of the organisation and its alleged close links with the Ministry of Tourism further alienated local people. Moreover, the perception of proprietorial control of their nascent tourism businesses represented a coercion and rew ard system of power (French \& Raven, 1959), familiar in the past but rejected now by the business community. Relationships between the two NGOs fared little better, there being limited cooperation and thus learning transfer and 


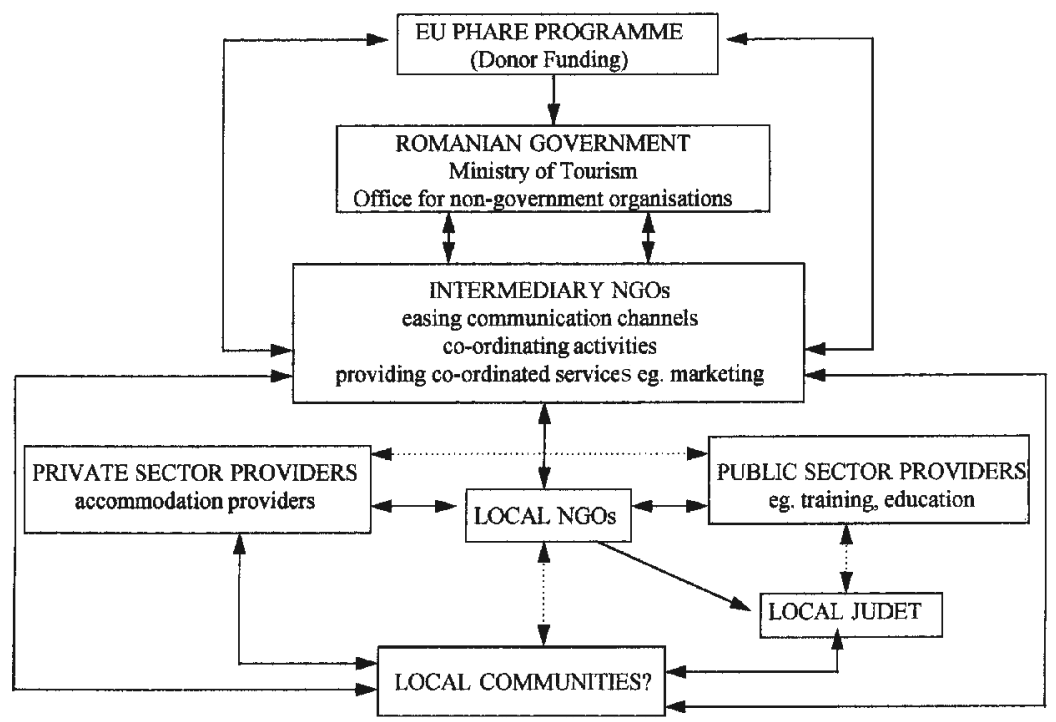

Figure 2 Romania: Proposed extension of partnership principles

it may be that the need to recognise and manage problems of competition and conflict between the two organisations was not addressed. This reflects Fowler's (1998) findings illustrating the inability to find a way of working that empowered both partners equally.

A donor-instigated review of progress, however, and an evaluation of networks and relationships has led to a recognition of the need to involve a greater number of interest groups and to work towards a decentralisation of power and of access to effective participation and collaboration, and the principles of partnership working are now being accepted by both government and the non-government organisations involved.

Figure 2 shows the projected partnerships, relationships and networks that it is hoped will revitalise rural tourism development processes in Romania. Stakeholders are clearly identified as business communities (those with a tangible stake in the programme), local government (județ), central government ministries, universities and training institutes, intermediate NGOs acting as an interface between local and national initiatives, grass-roots NGOs such as environmental organisations, and national and international organisations dedicated to the restructuring process. The complexities of stakeholder involvement are evident, each having different aims and objectives, unequal powers, varying administrative structures and cultures, and different levels of understanding and acceptance of the mutual benefits of collaboration. Nevertheless, there appears to be a political as well as a civic will to pursue such inclusive development practices, and importantly, a number of intermediary organisations have developed to bridge the consultation gap between work at the field level and 
national initiatives. On the part of government, this has manifest itself in the new Office for the Relations of Government-Non-government Organisations. This new organisation has much to learn from the Foundation for the Development of Civil Society, a US founded non-government organisation, also part funded by the EU Phare programme in Romania, which has four years' experience in developing a non-government sector in the country. Both organisations offer help in the building of partnerships and aim, in the longer term, to contribute to processes of decentralisation of power.

\section{Sustainable Tourism through Partnership in Bulgaria}

With the transition from a command to market economy, the tourism industry in Bulgaria has undergone substantial change. Tourism in Bulgaria before 1989 was characterised by group package tours, with little emphasis on attracting tourists on an individual or independent basis (Bachvarov, 1997). Since the fall of communism, however, the ind ustry has no longer been able to rely on the traditional strength of the domestic and former eastern bloc markets, which together accounted for around $80 \%$ of the market (Bachvarov, 1997), and is looking to extend its focus in order to compete more effectively within wider European and international markets. At the same time the state-dominated institutional structures which were set in place to develop the tourist industry are no longer well placed to service the needs of the country's industry adequately (Ilieva, 1998).

The Pirin mountain range stretches between the Mesta and Struma river valleys in south-west Bulgaria. The mountains form the focus of the region, currently a UNESCO protected site and recognised as a Category 2 area within worldwide national park classification. A number of small towns are scattered along each of the river valley areas, each having a distinct identity borne out by the traditional crafts, festivals and music of the area. Pirin has a number of notable and well-visited monasteries, and to the south the vineyards produce world famous wines in and around the architectural reserve town of Melnik. Further north, close to Bansko, is a relatively well-established winter sports resort, popular with domestic tourists although relatively new to the wider international market. To date, the expansion of winter sports and in particular skiing facilities has been limited owing to the restrictions imposed by the area's national park designation. However, the Pirin National Park Authority is now under increasing pressure to approve an ever-increasing number of applications for new developments within and close to the boundaries of the protected area.

The Pirin Tourism Forum (PTF) was set up as part of a project which ran from 1993 to 1997 and was funded by the United Kingdom Environmental Know How Fund (UKEKHF). The project was known as PREST - Pirin and Rila Eco and Sustainable Tourism. Heynes (1993) outlines the objectives and achievements of the project in its earlier stages. The key aim of the forum has been to ensure that a better balance is reached between tourism development and ecological sustainability. The Forum brings together representatives of the ten municipalities of the region, to work in partnership in advancing the tourism industry in Pirin, and promote the region as an area with a distinctive and coherent traditional culture and identity. In addition, PTF involves the Pirin National Park Authority (a branch of the National Forestry Committee), and acts as an interface 
between the locally based municipalities and the relevant departments of central government. The role of PTF in overcoming institutional fragmentation, political polarisation and public/private sector conflict in the area, through promoting a region based on partnership, has been invaluable.

A number of specific projects has been undertaken which illustrate the collaborative emphasis promoted by the PTF. The Forum prepared a comprehensive inventory of tourism facilities in the region, upon which a common marketing approach has been based. This has resulted in production of tourism guides and associated marketing materials which relate to each of the individual municipalities but which also have a shared style of presentation, setting each locality within a region-wide context. Similarly, PTF has been responsible for the promotion of local craft products under a corporate 'labelling' system for which a regional logo and quality assurance system are currently being developed. In effecting direct contact with tour operators and the tourist as a consumer, PTF coordinated a familiarisation trip to Pirin which incorporated the diverse range of places, customs, traditions and environment which the region has to offer within a coherent, single 'package'.

The PTF has endeavoured to bring together as many members of the community as possible. In broadening the 'communities of interest' served by the partnership, the PTF recently ran a competition for schools which focused on environmental education within the area and sought to develop community involvement in the work of the partnership. Future activities include consideration of a regionally consistent signposting scheme, a waymarking path which extends across the region and passes through a number of municipalities. The PTF has been well placed to overcome entrenched inter-municipality competitiveness, primarily as a result of its perceived political impartiality, whilst it has retained close links with its founding body, the UKEKHF. Similarly, it has bridged the gap between local and central government, by being actively involved in the preparation of a new tourism law for Bulgaria, and being highlighted by the Ministry of Trade and Tourism as potential model upon which new regional tourism organisations will be developed throughout the country.

Despite these successes, the continuing need for improved cooperation in Pirin is illustrated by current proposals being promoted by a number of municipalities which fall short of recognising the need to build a coherent strategy on a region-wide basis. The municipality of Gotse Delchev, for example, plans to build an extensive new tourism village in the mountain close to the town. Similarly, the municipality of Razlog, traditionally in open competition with its neighbour Bansko, has plans to develop a new skiing village on the slopes of the Pirin mountains which encroaches on some of the most ecologically sensitive areas of the national park. Research undertaken by the University of Sofia highlighted the discrepancies arising between actual requirements of the tourism industry and development planned and being implemented by the municipalities (Marinov et al., 1996). Despite much of the region's accommodation operating below capacity, public sector plans to provide additional accommodation and / or invest in improving existing stock, are being presented by virtually all of the municipalities. Whilst this situation indicates the need for further efforts to promote regional coordination of the public sector, it can also at least in part be 
attributed to an insufficient flow of information on the industry between public and private sectors.

As donor support expires in September 1999 (originally from the UKEKHF, and latterly from the UK government's Know How Fund), the PTF will increasingly become part of the state framework for tourism, operating as a new regional tourism authority as proposed by the 1997 law. Whether the balance within the partnership promoted by the PTF will continue within this new context remains to be seen. However, a perhaps more realistic assessment, as presented in the analysis of the shifting relations in Figures 3 and 4, underlines the influence of the new local tourism councils which will be closely associated with the municipalities. The addition of this new local tier may distance PTF from both the municipalities (which in turn have strong local business links) and the local communities. Maintaining a true partnership which is locally owned may prove difficult under these circumstances. Similarly, the growing need for PTF to become self-financing as donor support expires, questions the continuing perception locally that the organisation is neutral and apolitical. Left unchecked, this increasingly commercial orientation of the PTF is likely to undermine the achievements to date of its hitherto professional approach to a sector otherwise dominated by business and entrepreneurial interests. There is clearly scope to take the work of PTF further, but in doing so a better understanding must be developed of the criteria and mechanisms required to secure effective partnership working there.

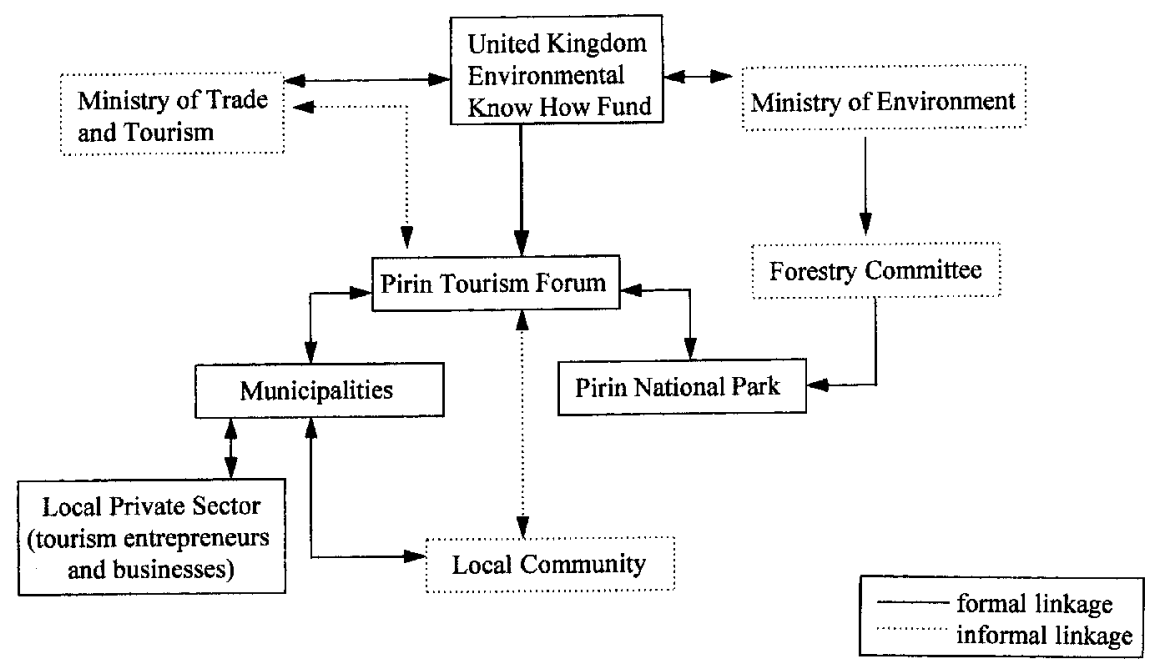

Figure 3 Current interstakeholder relationaships in Pirin 


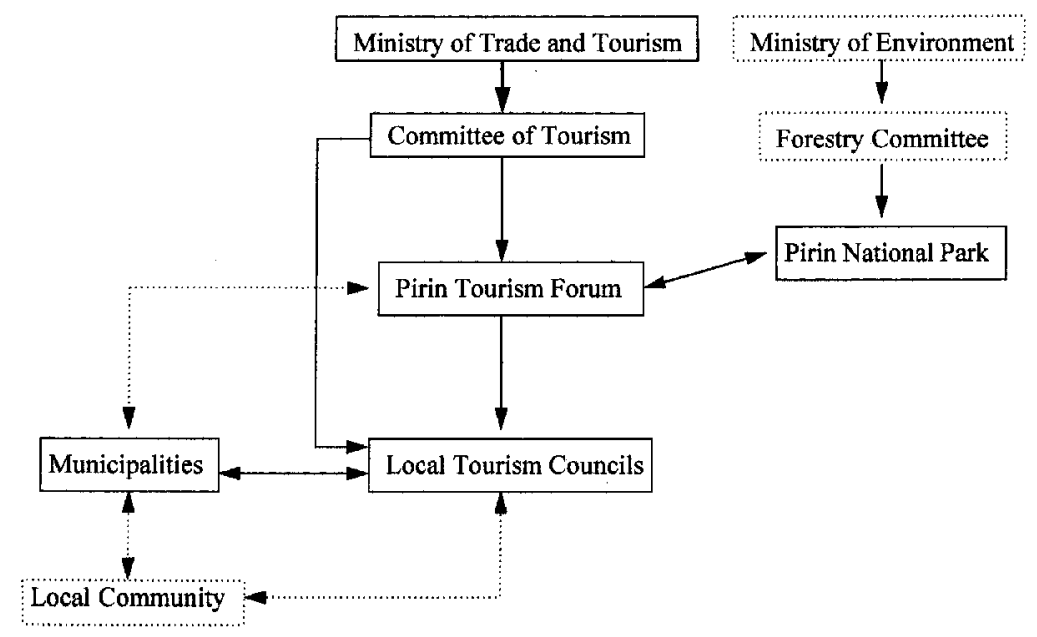

Figure 4 Emerging interstakeholder relationships in Pirin

\section{Comparative Evaluation of the Case Studies}

By revisiting the factors identified in the literature as those necessary for successful partnership working, based on Jamal and Getz's (1995) six fundamental propositions, the case studies can be analysed in a systematic way (Table 2). The analysis shows that, for two of the key criteria, clear commonalities exist between the cases. The first (proposition 2) highlights the influence of the post-socialist context on attitudes towards collaboration, through the lack of recognition of the reciprocal benefits which can be realised by such an approach. Whilst this is by no means exclusive to this context, it has been repeatedly identified as a key characteristic of it. Proposition 6, on the other hand, illustrates the influence of donor assistance on the perceived effectiveness of the partnerships. Where aims, structures and monitoring are an explicit requirement of donor organisation, they have often dominated the measurement of 'success'. This may have led to the lack of recognition of underlying, less tangible elements of collaboration, which the authors believe are the critical factors in defining sustainability in partnership working. Jamal and Getz themselves present their six propositions, as a 'starting point for further proposition development' (1995: 195). Whilst the six criteria do appear to cover the factors critical to success in partnership working, in order for them to be applied in a meaningful way, the extent to which they can be defined and measured should be taken into account. In response to this, and in order to discuss the comparative analysis in greater depth, the following prioritisation is suggested for the six propositions, in accordance with the extent of their measurability (Table 3).

It is important that the unequal nature of the propositions' measurability is taken into account within the analysis of partnership working. Taken a step 
Table 2 Comparative analysis of the case studies

\begin{tabular}{|c|c|c|c|}
\hline & & Romania & Bulgaria \\
\hline 1 & $\begin{array}{l}\text { Recognition of a high de- } \\
\text { gree of interdependence in } \\
\text { planning and managing } \\
\text { the domain / project }\end{array}$ & $\begin{array}{l}\text { Insufficient recognition of } \\
\text { the benefits of working to- } \\
\text { gether by NGOs, also pre- } \\
\text { cluding wider } \\
\text { involvement }\end{array}$ & $\begin{array}{l}\text { Recognition of the use of } \\
\text { inter-agency cooperation, } \\
\text { but with stakeholders par- } \\
\text { ticipating to meet their re- } \\
\text { spective agendas }\end{array}$ \\
\hline 2 & $\begin{array}{l}\text { Recognition of individual } \\
\text { and/or mutual benefits to } \\
\text { be derived from the col- } \\
\text { laborative process }\end{array}$ & \multicolumn{2}{|c|}{$\begin{array}{l}\text { Key actors saw joint and individual benefits as mutu- } \\
\text { ally exclusive } \\
\text { Competiton for scarce resources prevailed }\end{array}$} \\
\hline 3 & $\begin{array}{l}\text { A perception that } \\
\text { decisions arrived at will be } \\
\text { implemented }\end{array}$ & $\begin{array}{l}\text { A history of flawed com- } \\
\text { munication leading to a } \\
\text { lack of trust in 'promises' }\end{array}$ & $\begin{array}{l}\text { Trust in the partnership as } \\
\text { led by the NGO, but con- } \\
\text { tinuing mistrust between } \\
\text { stakeholders }\end{array}$ \\
\hline 4 & $\begin{array}{l}\text { The inclusion of key stake- } \\
\text { holder groups }\end{array}$ & $\begin{array}{l}\text { Insufficient meaningful in- } \\
\text { clusion of communities } \\
\text { that were already involved } \\
\text { in tourism development } \\
\text { prior to NGO creation }\end{array}$ & $\begin{array}{l}\text { Public sector interests in- } \\
\text { cluded, but marginal- } \\
\text { ised/overtaken by } \\
\text { municipality supported } \\
\text { private sector interests }\end{array}$ \\
\hline 5 & $\begin{array}{l}\text { The appointment of a } \\
\text { legitimate convenor to ini- } \\
\text { tiate and facilitate com mu- } \\
\text { nity-based } \\
\text { collaboration }\end{array}$ & $\begin{array}{l}\text { Clear leadership structure } \\
\text { but legitimacy not ac- } \\
\text { knowledged by local com- } \\
\text { munities }\end{array}$ & $\begin{array}{l}\text { Clear leadership structure } \\
\text { exists and has been effec- } \\
\text { tive in steering the course } \\
\text { of the partnership }\end{array}$ \\
\hline 6 & $\begin{array}{l}\text { Formulation of aims and } \\
\text { objectives, and } \\
\text { self-regulation of planning } \\
\text { and development }\end{array}$ & \multicolumn{2}{|c|}{$\begin{array}{l}\text { Clear structure, prioritisation of aims and objectives } \\
\text { and regular monitoring (primarily for and by external } \\
\text { donor organisation) }\end{array}$} \\
\hline
\end{tabular}

Table 3 Relative degrees of measurability of the factors critical to partnership success

\begin{tabular}{|c|c|}
\hline 6 & Formulation of aims and objectives \\
\hline 4 & The inclusion of key stakeholder groups \\
\hline 5 & $\begin{array}{l}\text { The appointment of a legitimate convenor to initiate and facilitate } \\
\text { community-based collaboration }\end{array}$ \\
\hline 1 & $\begin{array}{l}\text { Recognition of a high degree of interdependence in planning and } \\
\text { managing the domain/project }\end{array}$ \\
\hline 2 & $\begin{array}{l}\text { Recognition of individual and / or mutual benefits to be derived } \\
\text { from the collaborative process }\end{array}$ \\
\hline 3 & A perception that decisions arrived at will be implemented \\
\hline
\end{tabular}


further, this explicit recognition allows for the debate to be extended beyond an evaluation of formalised structures, to focus on some of the less tangible factors which are nonetheless crucial to the continued existence and further development of partnerships. In particular, the case studies illustrate where two key additional factors influence the sustainability of new working practices. These are: trust and sincerity, and the balance of power between stakeholders. Whilst the latter in particular has been referred to by others researching the subject, they remain of interest in terms of the additional dimension which can be added when these factors are layered over Jamal and Getzs' six propositions (1995).

As a result, the introduction of these concepts provides further insights into the analysis presented in Table 2 above. Whilst the Bulgarian case appears to have been relatively successful in terms of meeting most of the criteria put forward by the propositions, questions remain as to the detail and focus of the evaluation. For example, Proposition 1 accepts that there has been a recognition of interdependence between stakeholders, but does not take into account the conflicting plans which they continue to pursue alongside, and contrary to, their commitment to the partnership. Similarly, Proposition 3, identified as perhaps the least measurable factor, has been partially fulfilled, but the actual balance of power between the stakeholders is not adequately reflected in this evaluation. Trust in decisions being fulfilled is apparent, but without a full understanding of who makes the decisions, and the extent to which they represent the full common interests of the partnership. More specifically, aspects of the case study such as the dominance of municipality-based entrepreneurial interests over the objectives of the Pirin National Park Authority, also highlighted by Proposition 4, cannot be fully explored within such an analysis. Whilst the full range of stakeholders may indeed be involved (in effect, fulfilling Proposition 4), they are unlikely to maintain an equal influence on the work of the partnership and thus represent 'meaningful' participation.

A focus on the balance of power between stakeholders is also illustrated in the Romanian case, where prevalent power relations influenced, and indeed may have precluded, collaborative planning and inclusive development practices. Insufficient formal recognition has been given to the different power bases of quasi-government and non-government organisations, particularly within the post-socialist context. It should be borne in mind that the roles of such organisations are easily misunderstood even in areas where their work is well established, and it will take time for this 'third sector' to be fully appreciated in CEE. It is also important to note that the fundamental changes taking place in CEE alter working practices so significantly that they must inevitably alter the power biases that exist. These may be considered endemic to the post-socialist context where processes reinforced by opaque bureaucracies have had a tendency to operate in the interests of some stakeholders at the expense of others.

Whilst a clear leadership structure exists in both cases (proposition 5), its legitimacy and perceived sincerity is not taken into account in ascertaining whether common, political or individual interests are being met. Despite having been successful in gaining the support and trust of the local community, the PTF is likely to become more embedded within the emerging government framework in the future. This shift has the potential to undermine the benefits secured to date in terms of developing trust, which are largely attributable to the Forum's 
perceived impartiality. As a result, the PTF will have to pay close attention to the implications of increased government involvement if it is to maintain trust and perceived sincerity.

In contrast, whilst its leadership has hitherto lacked legitimacy owing to its central government associations, the Romanian case illustrates increasing opportunity for effective involvement at the local level. Successful partnerships are based on a legitimacy of power where the authority of a particular partner is accepted by all other groups as representative of joint interests. The likelihood of ANTREC's long-term viability is threatened by a continuing lack of legitimacy as perceived by local tourism businesses. It is possible that this situation will improve as understanding of NGOs and their central role in the support of partnership working increases. As a result, the negativity of the analysis presented in Proposition 5 for Romania obscures the fact that trust is likely to grow as local partnerships are increasingly able to distance themselves from the state and gain more direct control in their planning and decision-making processes.

\section{Conclusion}

The literature pointed to a need for empirical research and reporting on partnership working. More specifically, it called for a shift in focus tow ards identification of both general factors and those which are case specific. This comparative study has underlined the importance of making such a distinction, by identifying those issues shared by the cases and those which are not. Whilst many distinctions are drawn between the experiences, the common influences on their success can be attributed both to their shared post-socialist contexts and to the symptomatically complex nature of partnership working itself.

In the process of the analysis, the study identifies a need to focus further research on the intangible and immeasurable elements of collaboration and partnership working by adding a further dimension to previous discussions relating to factors critical for partnership success. The most easily measured criteria are often the most commonly used in established monitoring and evaluation processes, and contribute a great deal to the popular and politically perceived success or failure of a partnership. However, partnerships depend as much on the motivations, personalities and perceived roles of the participating stakeholders as they do on the formal structures and defined aims and objectives on which they are established. Whilst it is the very immeasurability of some factors that has led to a lack of previous attention to them, this analysis shows that they are critical to the overall sustainability of collaborative processes. Successful collaboration can exist, for example, without measurable targets, but it will fail completely without trust and sincerity. The complexities of relationships within partnerships and their environments mean that successful partnership working does not necessarily imply sustainability. Consequently, the analysis of partnerships must make a shift from a preoccupation with traditional measures of success, in order to take account of the less measurable, but more fundamental, factors critical to sustainability. 


\section{Correspondence}

Any correspondence should be directed to Lesley Roberts, Leisure and Tourism Management Department, Scottish Agricultural College, Auchincruive, Ayr KA6 5HV, Scotland, UK (1.roberts@au.sac.ac.uk).

\section{References}

Bachvarov, M. (1997) End of the model? Tourism in post-Communist Bulgaria. Tourism Management 18 (1), 43-50.

Brenner, R. (1993) The long road from serfdom and how to shorten it. In M. Maruyama (ed.) Management Reform in Eastern and Central Europe: Use of Pre-communist Cultures (pp. 81-109). Aldershot: Dartmouth Press.

Chapman, M. (1998) Effective Partnership Working. Area Regeneration Division, Good Practice Note No. 1. Edinburgh: Scottish Office, Edinburgh.

East European Newsletter (1998) 12 (8), 7.

Economist (1996) Fingers crossed, anon, 26 October, p. 61.

Elander, I. (1997) Between centralism and localism: On the development of local self-government in post-socialist Europe. Environment and Planning C: Government and Policy 15, 143-159.

Eyal, J. (1994) Same old guard, same old tune. Wall Street Journal, New York, 7 April.

Fowler, A.F. (1998) Authentic NGDO partnerships in the new policy agenda for international aid: Dead end or light ahead. Development and Change 29, 137-159.

French, J. and Raven, B. (1959) The bases of social pow er. In D. Cartwright (ed.) Studies in Social Power. Michigan Institute for Social Research.

Great Britain, Foreign and Commonwealth Office, Central European Department (1992) Current Situation in Eastern Europe. ERIA A G/1, April.

Gunn, C.A. (1994) Emergence of effective tourism planning and development. In A.V. Seaton, C.L. Jenkins, R.C. Wood, P.U.C. Dieke, M.M. Bennett, L.R. MacLellan and R. Smith (eds) Tourism: The State of the Art (pp. 10-19). Chichester: John Wiley.

Hall, C.M. (1994) Tourism and Politics: Policy, Power and Place. Chichester: John Wiley.

Hall, D.R. (1990) Eastern Europe opens its doors. Geographical Magazine, April, 10-15.

Hall, D.R. (1995) Tourism change in Central and Eastern Europe. In A. Montanari and A.M. Williams (eds) European Tourism. Chichester: John Wiley.

Hall, D.R. (1997) Going East? Landscape Design April, 8-10.

Heynes, K. (1993) The environmental know how fund and conservation through sustainable development. Revue de Tourisme 48, 3.

Horvath, T.M. (1997) Decentralization in public administration and provision of services: An East-Central European view. Environment and Planning C: Government and Policy 15, 161-175.

Hunt, J. (1993) Foreign investment in Eastern Europe's travel industry. Travel and Tourism Analyst 3, 65-85. London: Economic Intelligence Unit.

Hunya, G. (1996) Private economy in an etatist environment: The case of Romania. In H. Brezinski (ed.) The Economic Impact of New Firms in Post-socialist Countries. Bottom-up Transformation in Eastern Europe (pp. 107-115). Cheltenham: Edward Elgar.

Hunya, G. (1998) Romania 1990-2002: Stop-go Transformation, Centre for Research into Post-Communist Economies. Austria: Vienna Institute for Comparative Economic Studies.

Ilieva, L., (1998) Development of sustainable rural tourism in Bulgaria. In Proceedings from the Rural Tourism Management: Sustainable Options Conference. Ayr, Scotland, September.

Jamal, T.B. and Getz D. (1995) Collaboration theory and community tourism planning. Annals of Tourism Research 22 (1), 186-204.

Joppe, M. (1996) Sustainable community tourism development revisited. Tourism Management 17 (7), 475-479.

Kerpel, E. (1990) Tourism in Eastern Europe and the Soviet Union: Prospects for Growth and New Market Opportunities. Special Report No 2042. London: The Economic Intelligence Unit. 
Marinov, V., Vodenska, M., Atanasova, M. and Petrova, S. (1996) Tourism development research of the Bansko and Razlog municipalities. Tourist demand and the impact of tourism on the local economy. Project No. Bul/95/001. ILO/UNDP unpublished report, University of Sofia.

May, T. (1993) Social Research: Issues, Methods, and Process. Buckingham: Open University Press.

Murphy, P. (1985) Tourism: A Community Approach. London: Methuen.

Organisation for Economic Co-operation and Development (OECD) (1990) Partnerships for Rural Development. Paris: OECD.

Organisation for Economic Co-operation and Development (OECD) (1993) What Future for our Countryside? A Rural Development Policy. Paris: Paris.

Organisation for Economic Co-operation and Development (OECD) (1997) Review of Rural Policy: Partnerships in the United States. Paris: OECD.

Pickvance, C.G. (1997) Decentralization and democracy in Eastern Europe: A sceptical approach. Environment and Planning C: Government and Policy 15, 129-142.

Popescu, C. (1993) Romanian industry in transition. GeoJournal 29 (1), 41-48.

Reed, M.G. (1997) Power relations and community-based tourism planning. Annals of Tourism Research 24 (3), 566-591.

Robson, J. and Robson, I. (1996) From shareholders to stakeholders: Critical issues for tourism marketers. Tourism Management 17 (7), 533-540.

Schon, D.A. (1991) The Reflective Practitioner: How Professionals Think in Action. Aldershot: Ashgate Publishing.

Simmons, D.G. (1994) Community participation in tourism planning. Tourism Management 15 (2), 98-108.

Slee, B. and Snowden, P. (1997) Effective partnership working. Good Practice in Rural Development No. 1. Edinburgh: Scottish Office.

Turnock, D. (1996) Romania: Regional development in transition. Reconstructing the Balkans: A Geography of the New Southeast Europe. In D. Hall and D. Danta (eds) (pp. 157-168). Chichester: John Wiley.

World Tourism Organisation (1994) National and Regional Tourism Planning: Methodologies and Case Studies. London: Routledge.

World Tourism Organisation (1995) Yearbook of Tourism Statistics (47th edn). Madrid: WTO.

World Tourism Organisation (1997) Yearbook of Tourism Statistics (49th edn). Madrid: WTO.

Wyzan, M. (1997) Why is Bulgaria a land of failed reforms? Transitions 4 (7).

Yin, R.K. (1993) Applications of case study research. Applied Social Research Methods Series (Vol. 34). London: Sage Publications. 